\title{
Utilization of Waste to Increase the Added Value of Yard Land in Dharma Santi Hamlet
}

\author{
Luh Kartini ${ }^{1)}$; Anak Agung Ngurah Mayun Wirajaya ${ }^{2)}$; Made Sri Yuliartini ${ }^{3)}$ \\ ${ }^{1)},{ }^{2)},{ }^{3)}$ : Lecturer in Agrotechnology Study Program, Faculty of Agriculture, Warmadewa University
}

\begin{abstract}
PKM is similar to points II and III of the Women Groups Family Economic Empowerment program in Bali Province. The Family Revenue Improvement Efforts (UP2K) (Working Group Program II) were also established to properly manage land use through the Cool, Regulated, Beautiful, and Comfortable Yard of HATINYA (Working Group Program III). Nowadays, the yard land in the Dharma Santi hamlet, Ubung Kaja Village vary from large to narrow with comprising of various household activities capable of generating different amounts of waste. According to studies, these waste act as sources of organic material in supporting the creation of food security in each household. It is also useful in increasing nutrition and acts as an additional income for families that grow plants in pots to fill empty spaces in various corners of the yard. The current problems faced by households are 1). leaves and inadequate treatment of waste, 2). the waste disposal site is not yet owned, 3). the product is not properly packaged, 4). nutrient organic fertilizer, 5). the absence of additional ingredients to improve the quality of organic fertilizer. However, according to several studies, the following solutions can be performed 1). Counseling, training/monitoring and technology transfer, 2). Construction of disposal site, fermentation as well as adequate storage of organic materials and fertilizers, 3). Counseling, training and monitoring of packages, 4). Increase in nutrient content of organic fertilizer, and 5). Finding more organic material. This study aims to understand the technology of plant cultivation in the yard, increase the women group's knowledge in making organic fertilizer, ensure that partner groups have good business management, help create an entrepreneurial spirit which provides added value and provides additional income for the family. From this activity, the target output to be achieved is the partner group which utilizes household waste as organic fertilizer in the cultivation of plants in the yard and empty land around the partner group area.
\end{abstract}

Keywords: Women's group, yard use, and organic fertilizer. 


\section{Pendahuluan}

\subsection{Analisis Situasi}

Dusun Dharma Santi/ Banjar Dharma Santi terletak di jalan Tunggul Ametung, di Desa Ubung Kaja, Kecamatan Denpasar Utara, Kota Denpasar, Provinsi Bali. Desa Ubung kaja memiliki luas 459,35 Ha, dengan ketinggian tempat 500 meter dari permukaan laut. Adapun Batas Wilayahnya adalah sebagai berikut:

Sebelah Utara : Desa Sempidi

Sebelah Timur : Desa Peguyangan

Sebelah Selatan : Desa Ubung

Sebelah Barat : Padangsambian Kaja

Orbitasi desa Ubung Kaja adalah jarak ke ibu kota Kecamatan 1,50 Km, jarak ke ibukota kabupaten/kota adalah $5 \mathrm{~km}$, dan jarak ke ibukota provinsi adalah $8 \mathrm{Km}$. (Profil Desa Ubung Kaja, 2018).

Terkait dengan judul proposal ini yaitu PKM Peningkatan Nilai Tambah Pemanfaatan Lahan Pekarangan di Dusun/Banjar Dharma Santi, dimana kegiatan ini di fokuskan pada kegiatan ibu-ibu PKK yang ada di Dusun Dharma Santi, maka perlu diketahui analisis situasi dan posisi atau keberadaan ibu-ibu PKK nya. Adapun jumlah Ibu-PKK di dusun banjar Dharma Santi adalah sekitar 44 orang, dimana sebagian besar pekerjaan yang di tekuni adalah bervariasi baik sebagai pekerja atau pegawai swasta, pegawai negeri, usaha mandiri hingga ibu rumah tangga. Kondisi ini sangat potensial untuk mengembangkan dan meningkatkan ketahanan pangan yang sedang di galakkan oleh Pemerintah Indonesia untuk membarikan nilai tambah keluarga dan bermanfaat bagi kesehatan keluarga, melalui pengembangan Kawasan Rumah Pangan Lestari dengan memanfaatkan areal pekarangan yang ada. Kegiatan ibu-ibu PKK ini dalam rangka untuk mendukung program Tim PKK Provinsi Bali, dimana dalam program tersebut terdapat empat kelompok kerja (pokja) yang masing-masing memiliki program unggulan, seperti Program Pokja I, mengelola program PAAR (Pola Asuh Anak dan Remaja) dengan penuh cinta kasih sayang dalam keluarga, Program Pokja II, mengelola program Pemberdayaan Ekonomi Keluarga melalui UP2K PKK (Usaha Peningkatan Pendapatan Keluarga), Pokja III, mengelola Pemanfaatan lahan melalui Program Halaman Asri Teratur Indah dan Nyaman (HATINYA) PKK dan Pokja IV, mengelola Hidup Bersih Sehat di dalam Keluarga dan Lingkungan dengan PHBS (Prilaku Hidup Bersih dan Sehat) dan prilaku CERDIK (Cek kesehatan secara teratur, Enyahkan asap rokok, Rajin olah raga, Diet seimbang, Istirahat cukup, Kelola stres).

Program PKM ini terkait dengan program Pokja PKK Provinsi Bali poin II dan III yaitu, mengelola program Pemberdayaan Ekonomi Keluarga melalui UP2K PKK (Usaha Peningkatan Pendapatan Keluarga) (Program Pokja II) dan mengelola Pemanfaatan lahan melalui Program Halaman Asri Teratur Indah dan Nyaman (HATINYA) PKK (Pokja III).

Berdasarkan hasil observasi dilapang, saat ini permasalahan yang dihadapi mitra adalah 1). Dedaunan dan limbah rumah tangga belum diolah secara optimal , 2). belum dimiliki tempat penampungan limbah, 3). produk belum dikemas dengan baik, 4).nutrient pupuk organik, 5). belum adanya tambahan bahan lain untuk meningkatkan kualitas pupuk organik..

Diharapkan dengan adanya pengabdian kepada masyarakat yang didanai oleh Lembaga Pengabdian Masyarakat Universitas Warmadewa ini masyarakat Dusun/Banjar Dharma Santi akan mengalami peningkatan kemampuan dalam memanfaatkan lahan pekarangan dan limbah nya yang dapat diolah menjadi bahan organic dimanfaatkan sebagai sumber pupuk sehingga 
tanaman memberikan pertumbuhan dan berproduksi dengan baik, di pekarangan maupun dilahan kosong serta meningkatkan tambahan pendapatan pula.

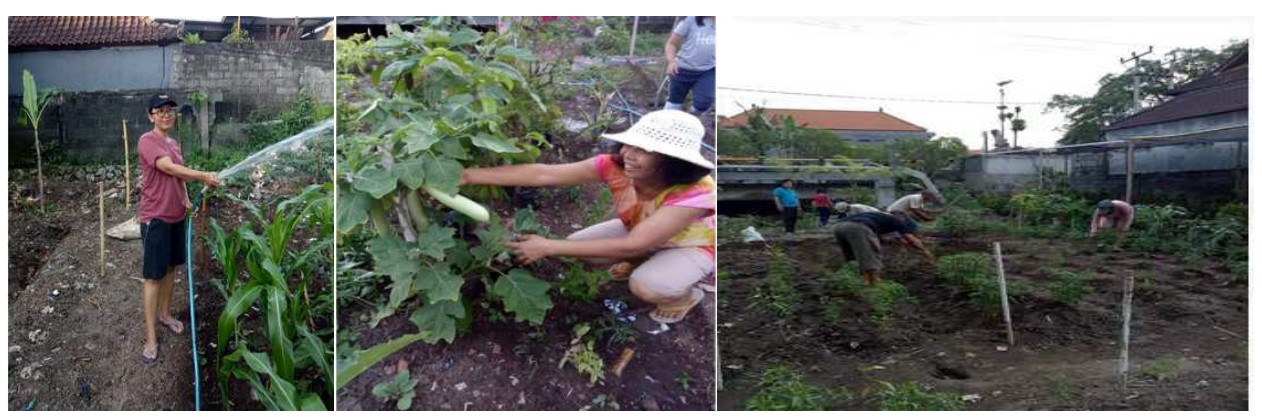

Gambar 1. Kondisi Umum Mitra

\subsection{Tujuan Kegiatan}

Tujuan kegiatan yang ingin dicapai pada kegiatan ini adalah :

1. Pemahaman teknologi budidaya tanaman di pekarangan rumah

2. Meningkatkan pengetahuan mitra dalam membuat pupuk organik

3. Kelompok mitra memiliki kemampuan dalam manajemen usaha yang baik.

4. Membantu menciptakan jiwa kewirausahaan bagi mitra sehingga memiliki nilai tambah dan mendapatkan penghasilan tambahan bagi keluarga.

\subsection{Manfaat Kegiatan}

1. Bagi kelompok mitra akan meningkatkan pendapatan dan kesejahteraan anggotanya melalui usaha pengolahan produk hasil pertanian dan kemandirian mitra.

2. Bagi Lembaga diharapkan kegiatan ini dipakai sebagai model pemberdayaan masyarakat dan dapat dipakai sebagai tempat pengembangan penelitian-penelitian .

3. Bagi Pemerintah diharapkan kegiatan ini dapat dipakai sebagai upaya pemberdayaan masyarakat dan menjadi model pengembangan kegiatan PKK dalam mengelola Pemanfaatan lahan pekarangan melalui Program Halaman Asri Teratur Indah dan Nyaman (HATINYA) PKK

\subsection{Tempat dan Waktu Pelaksanaan}

Pengabdian kepada masyarakat ini diselenggarakan di Kelompok PKK Dusun Dharma Santi di Desa Ubung Kaja, Kecamatan Denpasar Utara, Kota Denpasar-Provinsi Bali. Waktu pelaksanaan dimulai saat proposal PKM ini disetujui oleh Lembaga Pengabdian Kepada Masyarakat Universitas Warmadewa yaitu pada awal tahun 2019 dan berlangsung sampai akhir tahun 2019.

\section{Metode Pendekatan}

Dalam perencanaan pengabdian masyarakat ini metode yang akan digunakan untuk memudahkan serta melancarkan dalam penyerapan materi maka dilakukan :

1. Metode wawancara dan diskusi untuk mengetahui masalah yang dihadapi oleh mitra kerja 
2. Motode penyuluhan melalui tatap muka secara langsung, agar peserta didik mendapatkan ilmu pengetahuan mengenai penerapan teknologi pemanfaatan lahan pekarangan dengan menanam tanaman yang bermanfaat bagi keluarga dan tersedia hasil produksinya secara kontinu dengan memperhatikan kualitas dan kuantitas produk serta untuk membangkitkan jiwa kewirausahaan melalui manajemen usaha.

3. Praktek langsung akan dipandu oleh kami selaku pengabdi sekaligus sebagai instruktur sesuai dengan keahlian dibidangnya masing-masing dari tim pengabdian, sehingga peserta didik atau kelompok PKK dapat bertanam di pekarangan dangan baik dan benar dan bisa membuat langsung produk olahan hasil produksi tanamannya.

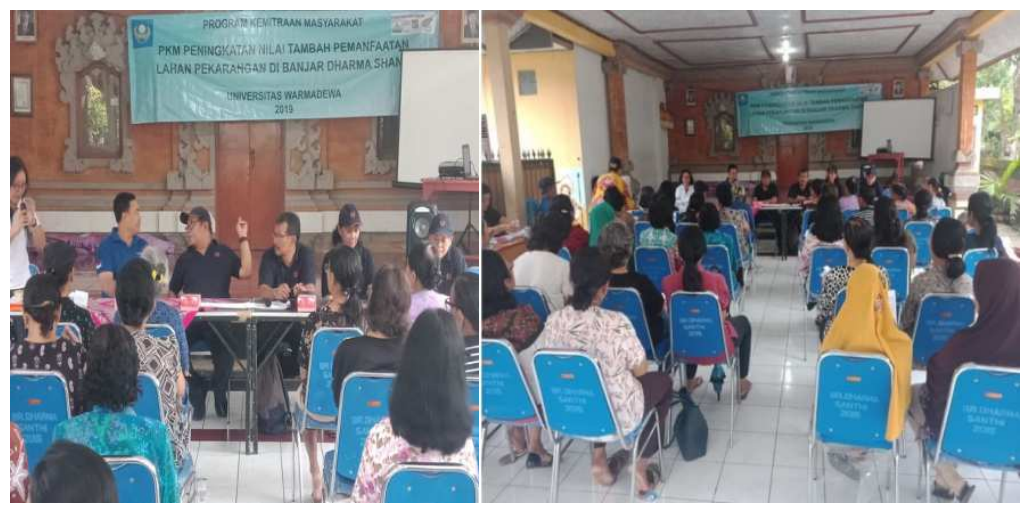

\section{Hasil Dan Pembahasan}

Dari permasalahan yang dihadapi, maka telah diberikan solusi dengan harapan tercapai target luaran seperti dibawah ini .

Tabel 1. Capaian Target Luaran Kegiatan

\begin{tabular}{|c|c|c|c|c|}
\hline No & Permasalahan & Solusi /Kegiatan & Target Luaran & CapaianTarget Luaran \\
\hline 1 & $\begin{array}{l}\text { Limbah padat organik } \\
\text { baik dari kotoran hewan } \\
\text { maupun dedaunan dan } \\
\text { limbah rumah tangga, } \\
\text { belum diolah secara } \\
\text { optimal dan memproses } \\
\text { /memproduksi pupuk } \\
\text { organik dari limbah } \\
\text { tersebut belum secara } \\
\text { intensif/hanya sewaktu- } \\
\text { waktu }\end{array}$ & $\begin{array}{l}\text { Penyuluhan,Pelatiha } \\
\text { n dan Pendampingan } \\
\text { dan alih teknologi. }\end{array}$ & $\begin{array}{l}\text { Mitra terampil } \\
\text { memanfaatkan } \\
\text { dan mengolah } \\
\text { kotoran padat } \\
\text { dan cair kelinci }\end{array}$ & $\begin{array}{l}\text { Telah dilakukan pelatihan } \\
\text { dan pendampingan SDM } \\
\text { pemanfaatan dedaunan } \\
\text { lahan pekarangan, limbah } \\
\text { rumah tangga dan kotoran } \\
\text { hewan, }(100 \%)\end{array}$ \\
\hline 2 & $\begin{array}{l}\text { Belum memiliki tempat } \\
\text { penampung dan } \\
\text { pengolahan bahan } \\
\text { organik untuk kegiatan } \\
\text { fermentasi dan } \\
\text { penyimpanan produk } \\
\text { pupuk organik }\end{array}$ & $\begin{array}{l}\text { Membangun tempat } \\
\text { penampungan, } \\
\text { proses fermentasi } \\
\text { dan penyimpanan } \\
\text { bahan dan puouk } \\
\text { organik yang } \\
\text { memadai }\end{array}$ & $\begin{array}{l}\text { Terbangunnya } \\
\text { dan dapat } \\
\text { digunakan } \\
\text { untuk kegiatan } \\
\text { mendapatkan } \\
\text { produk bahan } \\
\text { organik yang } \\
\text { berkualitas, }\end{array}$ & $\begin{array}{l}\text { Semakin banyak bahan } \\
\text { organik yg dapat diolah } \\
\text { dan berkualitas }(100 \%)\end{array}$ \\
\hline
\end{tabular}




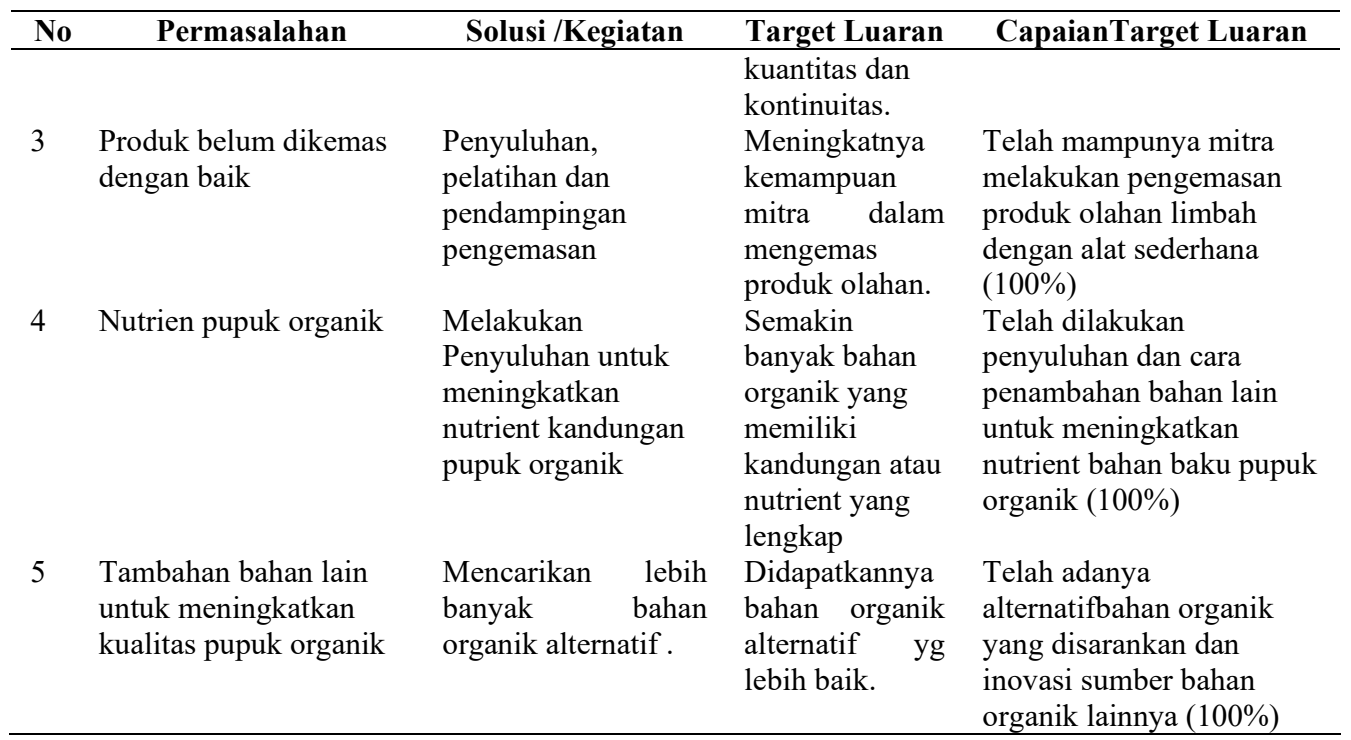

\section{Kesimpulan}

Kelompok mitra PKK dusun Dharma Santi di Desa Ubung Kaja dalam pengabdian ini telah mampu mengadopsi segala materi yang diberikan. Terbukti dalam upaya meningkatkan kualitas, kuantitas dan kontinuitas dari produk pemanfaatan limbah pekarangan kelompok mitra telah mau dan mampu mewujudkan bangunan agar dapat dipakai untuk proses pengolahan, fermentasi dan penyimpanan produk yang telah dihasilkan. Semakin baik tempat pengolahan produk diharapkan dapat menghasilkan produk olahan sesuai dengan rencana. Penerapan teknologi dalam proses fermentasi dapat dilakukan dengan baik. Produk telah dilakukan pengemasan namun masih sangat sederhana, diharapkan dapat bersaing dengan pupuk organik yang telah ada dipasaran serta lebih mudah ubahan baku organik menjadi pupuk organik untuk dipasarkan dan dapat dikenal lebih luas. Dengan pemanfaatan bahan organik dari limbah rumah tangga, dedaunan, rumput dan kotoran hewan yang ditampung dengan baik dan bersih akan memberi kontribusi tingkat kualitas pupuk organik sehingga semakin baik kualitas pupuk organik yang di hasilkan. Sumber makanan bahan baku organik yang menjadi kendala saat musim kemarau telah dicarikan solusi yang cocok disekitar lokasi dan melakukan inovasi campuran yang tepat. Pengabdian peningkatan nilai tambah pemanfaatan lahan pekarangan di dusun/banjar Dharma Santi ini dapat menjadi sumber tambahan pendapatan masyarakat khususnya ibu-ibu PKK dan memiliki prospek yang baik sehingga perlu disosialisasikan pada kelompok yang lain. Saran yang disampaikan dalam kegiatan ini adalah perlu dilakukan pembinaan secara berkesinambungan agar kelompok PKK Dusun Dharma Santi dapat melaksanakan kegiatan ini secara berkelanjutan.

\section{References}

[1] Firdaus, Muhammad. 2009. Manajemen Agribisnis. PT. Bumi Aksara. Jakarta.

[2] Gittinger J.Price. 1986. Analisa Ekonomi Proyek-Proyek Pertanian. UI Press. Jakarta. 
[3] Krisnamurthi, Bayu ndan Lusi Fausia. 2003. Langkah Sukses Memulai Agribisnis. Penebar Swadaya. Cimanggis. Depok.

[4] Nasution, Muslimin. 2002. Pengembangan Kelembagaan Koperasi Pedesaan Untuk Agroindustri. IPB Press. Bogor

[5] Profil Desa Ubung Kaja, 2018. Profil Desa dan Kelurahan , Desa Ubung Kaja, Kecamatan Denpasar Utara, Kota Denpasar-Provinsi Bali.

[6] Sa'id, Gumbira dan A. Harizt Intan. 2001. Manajemen Agribisnis. PT. Ghalia Indonesia dan MMA-IPB. Bogor

[7] Sumardjo., Jaka Sulaksana, Wahyu Aris Darmono. 2002. Teori dan Praktik dan Kemitraan Agribisnis. Penebar Swadaya. Cimanggis. Bogor

[8] Suratiyah, Ken. 2002. Ilmu Usaha Tani. Penebar Swadaya. Cimanggis. Bogor

[9] Zulkarnain, H. 2009. Dasar-dasar Hortikultura. Penerbit PT. Bumi Aksara-Jakarta

[10] http://www.litbang.pertanian.go.id/spp/sblp-2011

[11] https://selayarnews.com/sosialisasi-kawasan-rumah-pangan-lestari-begini-harapan-ketua-tp-pkkselayar/ 